\title{
A Estreita Relação entre Mulher e Água no Semiárido: o Caso do Programa um Milhão de Cisternas Rurais
}

\author{
The Close Relationship between Women and Water in the Semiarid: the Case of \\ a Million Rural Cistern Program
}

\author{
Emilio Tarlis Pontes \\ Universidade Federal de Pernambuco \\ tarlispontes@gmail.com
}

\section{Resumo}

No semiárido rural nordestino, o acesso descentralizado à água é uma questão histórica que, nas últimas décadas, ganha novos contornos com a articulação de diversas entidades associativas, nãogovernamentais e o Estado com a sociedade civil. Nesse contexto, entra em discussão o fundamental papel da mulher sertaneja, provedora da primeira água, aquela destinada a beber e cozinhar. Como ator social, exerce um papel chave no entendimento das relações entre gênero e convivência com o rural. $\mathrm{O}$ advento do Programa 'Um Milhão de Cisternas no Nordeste e suas implicações no cotidiano familiar, entrelaçado com a atuação da mulher serão analisados deste trabalho.

Palavras - chave: Mulher Sertaneja; Água; Semiárido; Cisternas

\begin{abstract}
In the rural semiarid region in Northeastern Brazil, the decentralized access to water is a historical issue that in recent decades has gained new contours due to the articulation of various associations, non-governmental organizations and the state, as well as civil society. In this context, it is discussed the fundamental role of the peasant woman, the first provider of water, whether for drinking or cooking. As a social actor, she plays a key role in understanding the relationship between gender and life in the countryside. The advent of the 'One Million Cistern Program' in Brazilian Northeast and its implications on family daily life, intertwined with woman's role in it, are examined in this work.
\end{abstract}

Keywords: Women Peasants; Water; Semiarid; Cistern. 


\section{Introdução}

Por uma imposição histórica, cujo trabalho não se propõe e não tem por objetivo minucializá-lo, as mulheres tiveram a sua identificação social relacionada com referência à casa, à família, às obrigações para com os maridos, filhos e a socialização familiar. Podese dizer que foi a partir da Revolução Industrial (Século XVIII) que essa condição começa a sofrer mudanças no seu perfil, pois a participação no mercado de trabalho, por exemplo, abriu novas possibilidades de lutas por direitos e mudanças das regras impostas e fixadas ao longo da História, como citado anteriormente (FISCHER, 2006).

Para Maciel (2007), a definição histórica e cultural dos papéis femininos e masculinos - espaço público: masculino; espaço privado: feminino - tem consequências diferenciais sobre um e outro em sua participação na sociedade e ainda é muito forte a ideia que os homens têm história e as mulheres, destinos. Atualmente, cada vez mais ambos os sexos interagem e se complementam, "desmontando a premissa de que o homem é o provedor da família e a mulher a rainha do lar" (FISCHER, 2006, p. 13). Em contrapartida, Peixoto (2009) considera que o 'destino histórico' das mulheres, tidas como as responsáveis pelo trabalho doméstico e familiar, com forte elo à baixa provisão de serviços socioassistenciais, tem contribuído para continuar a situação, principalmente relacionadas às camadas mais carentes, de exploração das mulheres.

E quando trata-se da questão da mulher sertaneja, nem sempre conectada e amparada com as benesses trazidas pelos últimos movimentos emancipatórios, é preciso uma análise a partir de sua realidade e de sua convivência histórica com que o semiárido lhe proporcionou, proporciona e poderá proporcionar, neste caso particular no que se refere ao item vital que é a água, ou melhor, da conquista da chamada primeira água (PONTES, 2010). Com isso, torna-se fundamental a valorização de experiências que favoreçam a participação das mulheres como sujeitos de direito às novas perspectivas que estão acontecendo, como as obtidas pela Casa da Mulher do Nordeste no vale do Pajeú pernambucano, através do Programa Um Milhão de Cisternas Rurais (P1MC), que serão tratadas neste trabalho.

\section{Água no Semiárido Brasileiro}

O binômio água e seca é um dos grandes desafios históricos no Nordeste semiárido, ou seja, a busca pela segurança hídrica para os sertanejos. Enfrentar esse desafio é ter em consideração o contexto de transformações no qual o semiárido está localizado, pois o mesmo não é uma região homogênea, com modificações socioeconômicas e culturais estruturais de grande impacto no cotidiano de sua população. A discussão em torno do trabalho político, educativo e mobilizatório que vem sendo realizado no semiárido, busca compreender o sentido das experiências de convivência com o mesmo.

Sabe-se que o semiárido brasileiro é um dos mais chuvosos do mundo. Conforme Braga (2004), o total de chuvas que caem anualmente é cerca de 700 bilhões de metros cúbicos, o equivalente a vinte vezes a barragem de Sobradinho, no Rio São Francisco. As soluções a serem buscadas têm como base a compreensão sobre a distribuição irregular das chuvas, pois como observa Lucio (2005) há dias chuvosos que levam à falsa ideia que a água é um transtorno. E não pode ser. Já foram inúmeras às vezes que o Nordeste sofreu com as grandes enchentes históricas.

Outro ponto a ser observado, como explicita Malvezzi (2007), é o déficit hídrico, não significando falta de chuva ou de água, mas a precipitação é menor do que a água que evapora. Para Sarmento (2005), uma solução desse problema seria através da sinergia hídrica, isto é, tirar vantagem derivada da conexão de uma região com uma reserva hídrica externa e perene (longe do poder da evapotranspiração do semiárido), da parcela hídrica para uso externo e não ocupar espaço na capacidade receptora, aproveitando dos excessos de vazão em períodos invernosos a serem armazenados em maior quantidade, ou seja, reduzir as perdas pela evaporação. Porém, os investimentos para tal são muito elevados e envolvem a discutidíssima transposição do rio São Francisco para alguns Estados nordestinos.

Schistek (2005), do Instituto Regional da Pequena Agropecuária Apropriada, elaborou um quadro sintético das necessidades hídricas no semiárido (Quadro 01):

Neste quadro, observa-se que há uma seletividade na qualidade e nas fontes da água para as famílias sertanejas. E nem sempre todas elas estão disponíveis para a população do semiárido. Muitas vezes, quando tem uma, falta a outra.

Conforme descrita por Mário Farias, da Diaconia, existe uma ideia mais simplificada que são as 'três águas para o semiárido', em entrevista ao autor (06/07/2009), ele a descreve:

\footnotetext{
A gente tem a clareza que uma família na zona rural precisa de três águas, em quantidade e qualidade diferentes. Ela precisa de uma água numa quantidade menor, mas numa qualidade maior. Aí ela
} 


\begin{tabular}{|c|c|c|}
\hline Denominação & Tipo de recurso hídrico & Utilização \\
\hline Água para a família & $\begin{array}{l}\text { Cisterna de captação de } \\
\text { água de chuva ou poço } \\
\text { raso ao lado da casa. }\end{array}$ & $\begin{array}{l}\text { Água para beber, } \\
\text { cozinhar, lavar louça, } \\
\text { banho. }\end{array}$ \\
\hline $\begin{array}{l}\text { Água para a } \\
\text { comunidade }\end{array}$ & $\begin{array}{l}\text { Água boa de pequenas } \\
\text { barragens largas e } \\
\text { profundas. }\end{array}$ & $\begin{array}{l}\text { Tomar banho, animais e } \\
\text { uso na pequena horta. }\end{array}$ \\
\hline Água de emergência & $\begin{array}{l}\text { Poços profundos ou } \\
\text { barragens largas e } \\
\text { profundas. }\end{array}$ & Todas as necessidades. \\
\hline Água para agricultura & $\begin{array}{l}\text { Pluvial em barragem } \\
\text { subterrânea; reservatório } \\
\text { para irrigação; cisterna } \\
\text { de calçadão. }\end{array}$ & $\begin{array}{l}\text { Irrigação para período } \\
\text { entre chuvas. }\end{array}$ \\
\hline
\end{tabular}

Quadro 01: Necessidade hídrica no semiárido. Fonte: Schistek, 2005.

precisa de uma segunda água, que é a água para o asseio, para uso geral na casa, lavar prato, porque não adianta você tomar água boa e lavar o prato com água suja. Precisa lavar o prato, tomar banho $e$ aí se contamina pelos poros, pelo nariz, pela boca. Essa quantidade aumenta, é uma quantidade maior, mas a qualidade não precisa ser tanta como da primeira. E tem a terceira água que é pra produção, porque a família tem que produzir a partir da pecuária e da agricultura. É assim: qualquer processo que não seja crescente nessa história, a família precisa garantir primeiro a água de primeira necessidade, depois precisa garantir a do uso geral da casa e depois, a de produzir. Até porque, essa, em quantidade menor, a família todo dia, se não tiver ela próxima a casa, vai ter que se deslocar pra ir pegar, porque todo dia ela bebe e prepara alimento. A limpeza, o banho é mais dispensável. Então, primeiro garantir essa água pra todo dia, aí depois garantir a outra água que não necessariamente é todo dia, e isso faz parte da rotina.
A difusão da ideia das três águas tem sido observada tanto nas famílias como em outras entidades que trabalham com manejo e captação de água de chuvas no Nordeste. Mesmo prosaica, sem grandes conjecturas, contempla bem a realidade do sertanejo e está presente em vários momentos, neste estudo.

A água e a seca, muitas vezes, são tratadas pelo lado técnico e termina por fugir da dimensão políticosocial da questão, esse quadro "engendrado pelos donatários da indústria da seca, gerou o processo de exclusão dominante no semiárido" (BATISTA, 2001, p. 32). Como retrata o geógrafo Manuel Corrêa de Andrade (1985), as ações reativas de construção de grandes açudes foram sendo executadas tendo por base as influências políticas locais. A açudagem pública foi acompanhada da privada, com muita água acumulada, mas subutilizada. Historicamente, por mais importante que venha a ser a açudagem e a irrigação, é claro, segundo Furtado (1967, p. 73) "que os benefícios dessas obras estão circunscritos a uma fração das terras semiáridas do Nordeste" e "a solução da seca não passa pela comporta, mas pelo comportamento" (PINTO, 2002, p. 402).

A quantidade de água precipitada no semiárido é suficiente para a vida humana. Mas a estrutura de armazenamento dessa, ao longo do tempo, não foi projetada para o sertanejo. Quanto mais extensa a 
lâmina d'água de um reservatório e mais raso ele for, maior será a evaporação, formando as imagens do chão rachado e esturricado. Quem tinha acesso a essa água, já não terá mais. Com isso:

as pessoas, em geral, migram; os animais morrem. Artistas captam essas imagens e as divulgam. Políticos pedem auxílio federal. Constroem grandes obras - nem sempre de forma honesta - mas, mais adiante, elas estarão secas de novo, por evaporação. Sustenta-se assim, ao infinito, a indústria da seca (MALVEZZI, 2007, p. 13).

A sustentabilidade hídrica do semiárido não tem uma única nem universal solução. As proposições a serem adotadas para as populações urbanas concentradas diferenciam-se da população rural, as vezes, bem difusa, por demandar volumes menores, instrumentos simplificados e de baixo custo, que implementadas, podem fazer a população rural conviver com as dificuldades hídricas regional em contraponto ao que ocorre no setor de irrigação pública ou privada destas áreas. No caso da zona rural, a água de beber, indispensável, pode ser eficientemente captada da chuva e armazenada em cisternas. Como assevera Malvezzi (op. cit., p. 09), é necessário "agasalhar a água da chuva".

Contudo, para um eficiente e duradouro armazenamento, são necessários planejamento e estudos, principalmente utilizando os conhecimentos sobre as bacias hidrográficas das determinadas áreas. Desde a década de 1980, pesquisadores já diziam isso, tal qual Molion (1985, p. 32): “a mitigação das secas deve basear-se num gerenciamento aprimorado dos recursos hídricos existentes, o que inclui a coleta e armazenamento das águas pluviais".

Um relato importante é o de Pinto (2002), quando cita que Euclides da Cunha, há mais de cem anos, já falava sobre a questão hidráulica no semiárido. Para ele, há duas proposições válidas: investir na média açudagem, ao invés vez de açudes imensos; construção de barragens de pedra seca, que detém a terra que a água traz das áreas desnudas e das culturas abertas, formando um solo úmido.

Já Suassuna (2005) é bem contundente quanto à questão da água no semiárido. Para ele, as secas sucessivas, incorporadas à grande carência nos planejamentos públicos com relação à gestão da água podem levar, em breve, a um colapso nesse setor, ou seja, faltará água para beber. E, historicamente, isso já tem acontecido repetidamente em vários municípios do semiárido, que ficaram com seus reservatórios com volumes críticos ou mesmo chegando ao nível zero.
Para Selborne (2002) é necessário estar atento as referências técnicas para a solução desse problema, sendo necessário desenvolver e mobilizar novas tecnologias para conservar, captar, transportar, reciclar e salvaguardar os recursos hídricos. Se as práticas forem desenvolvidas com êxito, precisam ser difundidas amplamente juntamente com o processo participatório que possa avaliar sua relevância para a possível aplicação em outras áreas. Contudo, problemas relacionados com a água são diferentes de região para região, exigindo um equilíbrio entre vários usos e soluções tecnológicas e tradicionais, como no caso aqui trabalhado, as cisternas para o semiárido nordestino.

Como se observa, resolver o problema da escassez de água não tem respostas e acordos consensuais, pois os interesses dos grupos não convergem. Diversos estudiosos e pesquisadores sugerem alternativas. Suassuna (2005) presume que é necessário estabelecer um sistema nacional de gerenciamento de recursos hídricos como os que já estão em prática em alguns estados; constituir um orçamento da águas; construir grandes represas e interligar bacias hidrográficas no Nordeste, utilizando racionalmente as águas; fazer uso da água do subsolo; tratamento de água em dessalinizadores; reutilização de águas servidas; prudência no uso das águas do Rio São Francisco e construção de cisternas rurais para a captação de água da chuva com fins de potabilidade.

Entre as várias possibilidades, uma factível e que está em plena atividade é a difusão do Programa Um Milhão de Cisternas, que parte do princípio da captação da água da chuva e da mobilização das famílias em prol da construção de um desenvolvimento local e conquista do direito à água para beber e cozinhar. E neste quesito, envolve-se diretamente o papel da mulher neste cenário de conquista.

\section{A Mulher e a Água - o Programa um Milhão de Cisternas}

Mesmo não sendo, em geral, as provedoras familiares, as mulheres também assumem um importantíssimo papel na ajuda financeira em seus lares, embora o homem se mantenha como chefe e possua mais reconhecimento político. No sertão, essa realidade ainda persiste e elas nem sempre estão praticando atividades remuneradas.

Contudo, "embora subjugadas, desempenham um papel relevante na reprodução da unidade doméstica e têm provado ser poderosas, na esfera doméstica das áreas rurais do semiárido" (BRANCO, 2000, p. 200). Importância que cresce se for considerado que, devido 
à emigração masculina, muitas sertanejas se tornam chefes de família.

Melo (2005) destaca que a mulher agricultora sertaneja possui uma íntima ligação com a água, sendo praticamente a responsável por essa para o consumo da família (beber, preparar alimentos e higiene) além das outras atividades que envolvem o uso da água para agricultura e o trato de animais de pequeno porte. Mesmo assim, ela ainda não é plenamente partícipe ativo na elaboração dos programas relacionados à água.

Conforme Branco (2000), as mulheres, no contexto semiárido versus seca, desempenham um papel importantíssimo, mesmo tendo sido discriminadas no processo de planejamento de desenvolvimento da sociedade rural nordestina. A desatenção por parte dos formuladores de políticas públicas e também de estudiosos marca a "invisibilidade" (op. cit., p. 22) das mulheres na problemática da seca, onde elas têm sido visualizadas como atores passivos e, para se ter uma visão mais completa da questão, não é possível deixar de focalizá-las, afinal:

as mulheres despontam como um elemento relevante, ao lidarem, especificamente, com a seca. Elas não migram, somente, em busca de um emprego remunerado, mas assumem, também, quando necessário, devido à ausência dos homens, a chefia das famílias rurais, além de se organizarem em grupos [grifo nosso] (ibidem., p. 22-23).

Mesmo com essa invisibilidade, Fischer (2006) considera que a mulher sertaneja sempre participou do espaço público, na produção de sobrevivência e guardiã da cadeia alimentar.

$\mathrm{Na}$ sociedade do semiárido afetada pela seca, o engajamento das mulheres no trabalho assalariado é muito oportuno. É de fundamental importância que tenham oportunidade de exercerem atividades alternativas que gerem renda, embora tenha-se em vista as limitações do mercado de trabalho e a subordinação cultural construída sobre o confinamento e as obrigações estritamente domésticas que, na prática, não geram muitas alternativas locais. Nas épocas de crise, suas atividades produtivas tornam-se visíveis. Todavia, "em um contexto onde o patriarcado é muito forte, fica implícito que elas não devem expressar o poder que têm" (BRANCO, 2000, p. 35). Embora os homens saibam desse potencial, muitas vezes preferem não demonstrá-lo explicitamente.

Branco (2000) e Melo (2001) lembram que, na ausência de ações governamentais efetivas e mais abrangentes, as mulheres vêm lutando pela convivência com o semiárido, mesmo com suas iniciativas sendo subestimadas. No sertão, atividades públicas vem cada vez mais ganhado espaço no universo feminino como o trabalho assalariado e a mobilização política. Ao assumirem a chefia das famílias, as mulheres possibilitam seus maridos a migrarem durante as grandes estiagens. As esposas desses homens são conhecidas como "viúvas da seca", pois seus maridos, algumas vezes, formam outra família no lugar aonde vão e não mais voltam (BRANCO, 2000; GALINDO, 2008). Elas são conscientes dos problemas socioeconômicos e políticos gerados pela histórica indústria da seca. Ao se engajarem na busca pela mitigação dos efeitos da seca, se envolvem na construção de um novo espaço, resultado do seu ingresso no domínio público, participação de movimentos, associações e outras entidades, incorporando novas relações de saber e poder.

A labuta, em geral, começa cedo. A partir, mais ou menos, dos sete anos as mulheres são introduzidas nas atividades agrícolas e ficam até a velhice. Sales (2007), observa que, no semiárido, muitas meninas entre oito e doze anos carregam água, alimentam animais, cuidam das casas e dos irmãos, ou seja, desde a infância já estão inseridas no grupo de trabalho familiar e na roça. Porém, existe uma desvalorização do trabalho da mulher, como coloca Fischer (2006, p. 44-45):

a jornada cotidiana da mulher no campo é, geralmente, subestimada, uma vez que o trabalho da roça fica subsumido no doméstico, considerado não-trabalho, visto como extensão de suas atribuições de mãe/esposa/dona-de-casa, naturalmente considerada parte das relações afetivas. A jornada de trabalho da mulher rural inclui o cuidado das crianças, dos doentes, dos velhos, o apoio psicológico para manter a família unida, o abastecimento d'água, que, muitas vezes, supõe seu deslocamento diário até três, quatro quilômetros [grifo nosso], e o da lenha [...] isso perfaz uma superjornada que se inicia geralmente às 4 horas da manhã e só termina com a chegada dos filhos da escola noturna. A mulher é a última a deitar e a primeira a acordar.

Dentro dessa ótica de observação da situação histórica da mulher nordestina, o Programa 'Um 
Milhão de Cisternas Rurais' (P1MC) estabelece critérios para escolha das famílias que serão mobilizadas e terão cisternas. O primeiro ponto é, exatamente, as casas terem mulheres como a chefe de família. Esse é um aspecto que desponta dentro de um cenário marcadamente machista desde os primórdios das formações em sociedade no mundo. Assim, a revalorização da mulher sertaneja é um modo de compreender a situação sócio-histórica do sertão nordestino. Elas, que se supõe passar ao largo dos principais movimentos políticos, sociais e econômicos, são forças que precisam ser valorizadas, assumindo seu lugar de liderança familiar e comunitária (FISCHER, 2001).

É necessário que as mulheres sejam reconhecidas como agentes do espaço público, por sua luta pela terra, água e pelo acesso aos programas de desenvolvimento rural. A sua condição está imbricada em uma rede que vai além de sua identificação com a esfera doméstica. A medida que esse processo está avançando, é admitido que o movimento de lutas e mobilização social está fornecendo um aprendizado político para que as mulheres exerçam ações que possam diminuir as subordinações de gênero.

O papel das mulheres no semiárido é um retrato de como são fortes e poderosas, mesmo nem todas tendo consciência disso. São elas que sustentam a unidade familiar, jovens ou idosas, trabalhadoras domésticas ou intensamente no campo e continuam resistindo e lutando pela sobrevivência encontrando formas dentro da lógica da convivência. Por isso, o fim das longas caminhadas, com peso das latas d'água na cabeça, propiciado pelas cisternas, é um começo para uma boa convivência no semiárido. Cavalcanti (2003) lembra que para Macena, no período da seca, as mulheres sertanejas podem caminhar de três a seis quilômetros levando latas na cabeça de 16 a 18 litros. Em alguns casos, chegam a andar mais de dez quilômetros por dia, transportando 150 latas, equivalendo a 2.700 litros de água/mês, esforço compartilhado, muitas vezes, com crianças. E, claro, a cisterna traz alívio para muitos homens que também carregam galões de água (Figura 1).

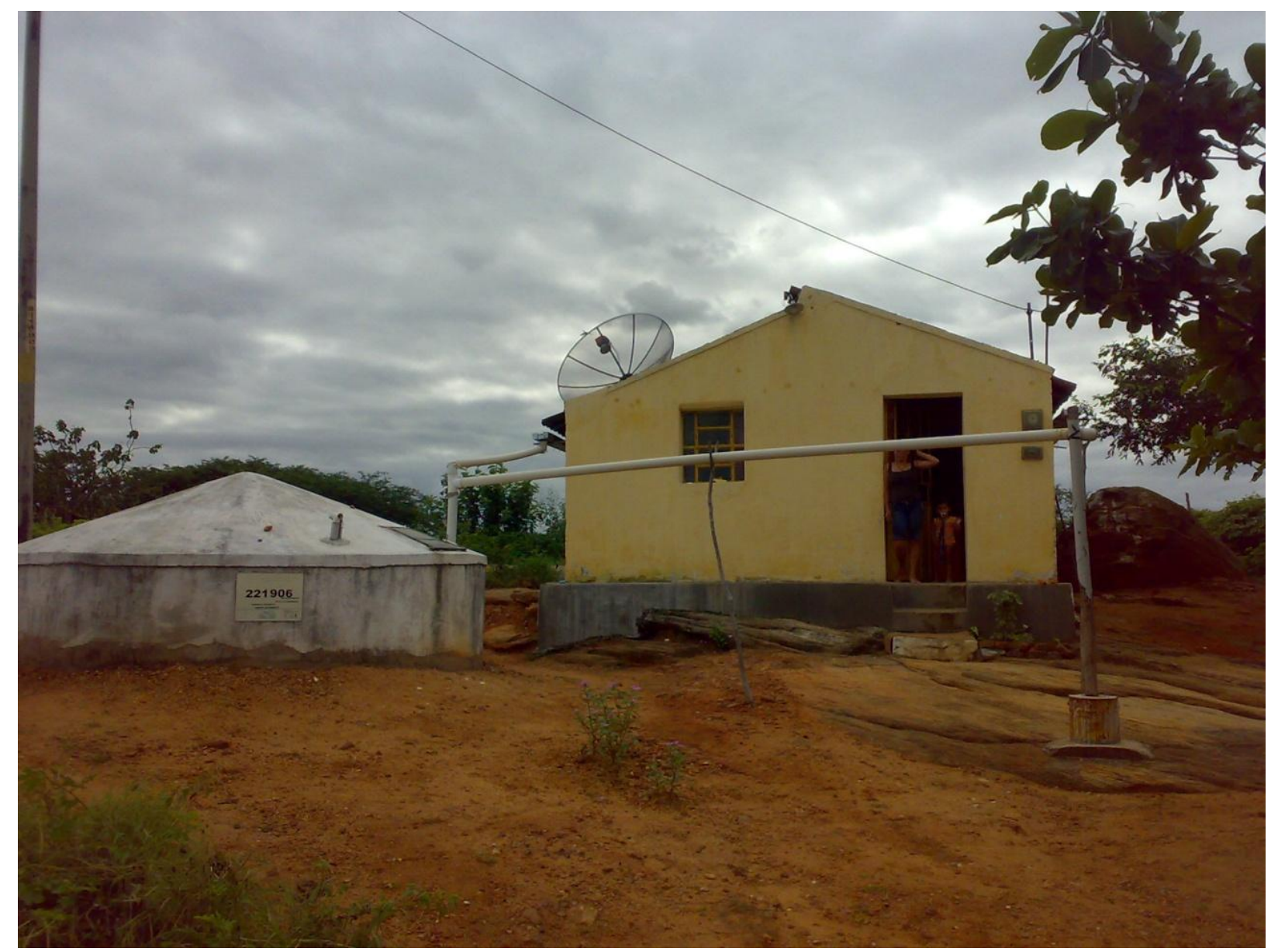

Figura 1: Cisterna no município de Afogados da Ingazeira, vale do Pajeú - PE. Fonte: acervo do autor. 
O negligente foco em relação ao contingente feminino conduz a uma compreensão limitada do impacto da seca e do feedback de sua população. Sem o olhar para o papel das mulheres diante dessa situação as análises ficam incompletas, pois envolvem um vasto leque de questões e possibilidades. Melo (2005) considera que os estudos de gênero na realidade rural pouco objetivam a inclusão da mulher na agricultura e nas políticas de desenvolvimento. Essas políticas públicas para o semiárido, geralmente, quando não ficam no papel, não contemplam ou, quando tratam de incluir o tema gênero, fazem muito deficientemente, o que é um atraso pois mais da metade do semiárido é composto por mulheres que participam ativamente dos trabalhos do setor agropecuário, isto é, “os vários programas até então criados para desenvolver a região em decorrência das secas (...) não incorporam devidamente a questão de gênero, tornando-os, praticamente, exclusivo dos homens agricultores" (op. cit., p. 02).

Nem tudo ocorre conforme as formulações e conceitos dos estudiosos do assunto. A realidade muitas vezes passa longe da beleza dos intuitos e das frases de efeito dos formuladores de políticas públicas e também dos pesquisadores. Há críticas tanto aos programas emergenciais como aos de convivência com o semiárido, que precisam ter maior abrangência quando se trata de gênero, inclusive o próprio P1MC.

\section{Considerações Finais}

Importante ressaltar o papel da mulher nesse processo. Além de ser um dos primeiros critérios de escolha, elas também participam ativamente das reuniões nas associações e se envolvem na mobilização.

As casas onde moram adultos acima de 65 anos, ou tenham deficientes mentais/físicos, também estão entre as prioritárias. Esse é outro aspecto que gera muita dificuldade para as famílias carentes, pois além da falta de emprego e recursos hídricos, ainda precisam lidar diariamente com pessoas que requerem um cuidado especial e um atendimento mais próximo, demandando tempo. Com a cisterna e a água, muitos desses cuidados podem ser feitos e condições de saúde e higiene estarão mais acessíveis. Doenças diarreicas ligadas a água poluída e ao saneamento inadequado estão entre as principais causas de morte de crianças menores de cinco anos.

Um estudo de caso feito por Luna, Costa e Brito (2009), avaliando o impacto do P1MC na saúde das famílias do agreste pernambucano, verificando a ocorrência de diarreia, é de grande relevância como demonstrativo da ação desse programa. Conforme os autores, a água é um dos principais fatores no processo de doenças diarreicas. Em sua pesquisa, foram investigadas 412 famílias com e 412 sem cisternas. Estimaram o risco e a incidência de episódios de diarreia nestas famílias que tinham crianças com idade até cinco anos. O resultado final foi que o risco de diarreia nas famílias sem cisterna era $79 \%$ maior do que nas famílias beneficiadas, desde que tomados os devidos cuidados no manuseio das cisternas, o que mostra um excelente nível de eficiência quanto à saúde dos usuários.

Pode-se dizer que, na prática, além da questão da saúde, a água acessível perto de casa durante todo o ano é outra importante conquista, minimizando as longas caminhadas, quase sempre feitas por mulheres e crianças, que os sertanejos faziam em busca de água. O P1MC vem trazendo uma melhor qualidade de vida para elas, exemplificado na diminuição e/ou redução do grande esforço físico das latas d'água em longos percursos até o lar e no seu envolvimento e engajamento na busca por novas conquistas que se traduzam em benefícios para suas comunidades, vide a grande quantidade de mulheres líderes de associações no Vale do Pajeú pernambucano.

\section{Referências}

ANDRADE, Manuel Corrêa. Classes sociais e agricultura no Nordeste. Recife: Massangana, 1985.

BATISTA, Laurentino Fernandes. Água, mais água... é a solução para o semiárido? In: BATISTA FILHO, Malaquias. Viabilizações do semiárido nordestino. Recife: IMIP, 2001, p. 32-37.

BRAGA, Osmar Rufino. Educação e convivência com o semiárido: introdução aos fundamentos do trabalho político educativo no semiárido brasileiro. In: KÜSTER, Ângela; MATTOS, Beatriz Helena Oliveira de Mello. Educação no contexto do semiárido brasileiro. Fortaleza: Fundação Konrad Adenauer, 2004, p. 25-44.

BRANCO, Adélia. Mulheres da seca: luta e visibilidade numa situação de desastre. Recife, EDUFPB, 2000.

CAVALCANTI, Edneida. Para compreender a desertificação - uma abordagem didática e integrada. Recife: FUNDAJ, 2003.

FILHO, José Coelho de Araújo (et al). Solos dominantes no estado de Pernambuco. In: PERNAMBUCO. Secretaria de Ciência, Tecnologia e 
Meio Ambiente. Atlas Bacias Hidrográficas de Pernambuco. Recife: SECTMA, 2006, p. 30-33.

FISCHER, Izaura Rufino. O Estado e a questão feminina na reforma agrária. Ciência e Trópico. Recife, v. 29, n. 2, p. 405-417, jul./dez, 2001.

FISCHER, Izaura Rufino. O protagonismo da mulher rural no contexto da dominação. Recife: Massangana, 2006.

FURTADO, Celso. Uma política de desenvolvimento econômico para o Nordeste. $2^{\mathrm{a}}$ ed. Recife: SUDENE, 1967.

GALINDO, Wedna Cristina Marinho. Intervenção rural e autonomia: a experiência da Articulação no Semiárido (ASA) em Pernambuco. Recife: EDUFPE, 2008.

LUCIO, Cláudio José Marinho. Os recursos hídricos em Pernambuco. In: MESSIAS, Arminda Saconi; COSTA, Marcos Roberto Nunes. (Org) Água fonte de vida. Recife: UNICAP, 2005, p. 55-65.

LUNA, Carlos Feitosa; COSTA, André Monteiro; BRITO, Ana Maria de. Avaliação do impacto do Programa 'Um Milhão de Cisternas Rurais' (P1MC) na saúde: ocorrência de diarreia no Agreste Central de Pernambuco. In: XI SEMINÁRIO SOBRE VIABILIZAÇÃO DO SEMI-ÁRIDO DO NORDESTE. 2009. Anais, Recife, 2009. 1 CD-ROM.

MACIEL, Elizabeth Nunes. Mulheres na periferia urbana: gerando pequenos negócios. In: TEDESCO, João Carlos; PASTORE, Elenice. Ciências sociais: temas contemporâneos. Vol. 2: trabalho e movimentos sociais. Passo Fundo: EDUPF, 2007, p. 154-190.

MALVEZZI, Roberto. Semiárido. Uma visão holística. Recife: Imprinta Express, 2007.

MELO, Ligia Albuquerque de. Relações de gênero na convivência com o semiárido brasileiro: a água para o consumo doméstico. 2005. Disponível em: www.fundaj.gov.br/geral/nesa/textos/genero_conviven cia.pdf Acesso em 27.abr.11.

MOLION, Luis Carlos Baldicero. Secas: o eterno retorno. Ciência Hoje, v. 3, n. 18, p. 26-32 mai/jun, 1985.

PINTO, Otavio Augusto Sitônio. Dom Sertão, Dona Seca. João Pessoa: A União, 2002.
PEIXOTO, Socorro Letícia Fernandes. As mulheres face às contradições do mundo atual. Agrofloresta. Fortaleza, ano 3, v. 3, abril, 2009.

PONTES, Emílio Tarlis Mendes. Transições paradigmáticas: do combate à seca à convivência com o semiárido nordestino, o caso do Programa Um Milhão de Cisternas no município de Afogados da Ingazeira - PE. Recife: EDUFPE, 2010.

SALES, Celecina de Maria Veras. Mulheres rurais: tecendo novas relações e reconhecendo direitos. Estudos Feministas, Florianópolis, v. 15, n. 02, p. 437-443, mai/ago 2007. Disponível em: http://www.scielo.br/pdf/ref/v15n2/a10v15n2.pdf Acesso em: 13.mar.11.

SARMENTO, Francisco Jacome. Transposição do rio São Francisco. Realidade e obra a construir. Brasília: EDICEL, 2005.

SCHISTEK, Harald. A água no semiárido brasileiro. 2005. Disponível em: http://www.irpaa.org.br. Acesso em: 26.jun.09.

SELBORNE, Lord. A ética do uso da água doce: um levantamento. Brasília: UNESCO, 2002.

SUASSUNA, João. Potencialidades hídricas do Nordeste brasileiro: o uso múltiplo da água e a importância do Rio São Francisco. In: MESSIAS, Arminda Saconi; COSTA, Marcos Roberto Nunes. Água fonte de vida. Recife: UNICAP, 2005, p. 77-98.
Recebido em 28 de dezembro de 2011. Aceito em 24 de junho de 2012. 